\title{
Treatment of fistula-in-ano with cyanoacrylate glue with and without prior seton placement in rats ${ }^{1}$
}

\author{
Gustavo Tominaga Romero ${ }^{\mathrm{I}}$, Carlos Henrique Marques dos Santos ${ }^{\mathrm{II}}$, Pedro Carvalho Cassino ${ }^{\mathrm{III}}$, Maçanori Odashiro ${ }^{\mathrm{IV}}$, Gisele \\ Zocoller Senov ${ }^{\text {, Gabriela Flávia Aléssio }}{ }^{\text {II }}$
}

DOI: http://dx.doi.org/10.1590/S0102-865020160060000003

IMD, Resident, Department of Surgery, Universidade Federal do Mato Grosso do Sul (UFMS), Brazil. Acquisition, interpretation and analysis of data IIPhD, Associate Professor, Department of Surgery, UFMS, Campo Grande-MS, Brazil. Conception and design of the study, interpretation of data, manuscript writing, critical revision.

IIIMaster, Fellow PhD degree, Postgraduate Program in Saúde e Desenvolvimento da Região Centro-Oeste, UFMS, Campo Grande-MS, Brazil. Technical procedures, acquisition of data.

${ }^{\text {IV }} \mathrm{PhD}$, Associate Professor, Department of Pathology, UFMS, Campo Grande-MS, Brazil. Histopathological examinations.

${ }^{v}$ Graduate student, School of Medicine, UFMS, Campo Grande-MS, Brazil. Acquisition, interpretation and analysis of data.

${ }^{\mathrm{VI} G r a d u a t e}$ student, School of Pharmacy, UFMS, Campo Grande-MS, Brazil. Acquisition, interpretation and analysis of data.

\begin{abstract}
PURPOSE: To evaluate the efficacy of ethyl-cyanoacrylate in the treatment of fístula-in-ano in rats with and without prior seton placement.

METHODS: Thirty rats Wistar with fístula-in-ano produced surgically, distributed in three groups: group A (ethyl-cyanoacrylate) treated by application of ethyl-cyanoacrylate into fístula tract; group B (seton + ethyl-cyanoacrylate) - seton placement followed by application of ethyl-cyanoacrylate into fístula tract, 30 days later; group C (control) - no treatment. After 60 days the animals were submited to euthanasia and the specimens were analyzed by pathologist. The results were analyzed by Chi-square test with significant value of $\mathrm{p}<0.05$.
\end{abstract}

RESULTS: One animal of group B died. Were found tracts fully healed: 7, 5 and 2, in groups A, B and C, respectivelly. There was a statistically significant difference between groups $A$ and $C(p=0.02)$. When joined all animals treated with glue $(A+B)$ compared to group $\mathrm{C}$ there was also statistically significant difference $(\mathrm{p}=0.02)$.

CONCLUSIONS: The use of ethyl-cyanoacrylate glue was effective in closing anal fistulae in rats. There was no advantage in the prior application of seton.

Key words: Anus Diseases. Therapeutic Uses. Cyanoacrylates. Rats. 


\section{Introduction}

The anal fistula is a disease defined as the abnormal communication of the intestinal epithelium (anal canal or rectum) and skin ${ }^{1}$. The incidence in the general population is highly variable, and found values between 1.04 to 2.32 of new cases per 100000 inhabitants in some european countries ${ }^{2}$, and mainly affects the age group between 30 and 50 years, with preference for $\mathrm{men}^{3}$.

The main cause of anal fistula is related to anal glands, located in the intersphincteric plan ${ }^{2,3}$. The obstruction of the drain ducts of the gland by trauma, inflammation, or fecalith causes abscess formation in intersphincteric space, and may evolve to fistula in $30 \%$ to $40 \%$ of cases. Other conditions such as inflammatory bowel disease (ulcerative colitis, Crohn's disease), infections (actinomycosis, tuberculosis, lymphogranuloma venerius, AIDS), cancer, surgical trauma and others represent approximately $20 \%$ of causes ${ }^{4,5}$.

There are several therapeutic modalities that have in common three main objectives: control of sepsis, fistula closure and maintenance of continence ${ }^{6}$. Traditional methods are the surgical approaches, however, despite good results, have significant incontinence rates ${ }^{7}$.

Other less invasive treatment varieties has been used in the past years in order to minimize the risk of incontinence ${ }^{8}$. Among them is the biological colagen plug ${ }^{9}$, VAAFT (Video-assisted anal fistula treatment $)^{8}$, LIFT (Ligation of intersphincteric fistula tract $)^{10}$ and biological glues. Some authors have recommended that prior to the execution of some of these proceedings, a seton shold be applied for a few weeks, which could improve the effectiveness of those methods ${ }^{10}$.

Among adhesives used for this purpose, the fibrin glue is the most used ${ }^{11}$, however, its routine use is still limited due to its high $\operatorname{cost}^{12}$. Due to this fact, another glue, like cyanoacrylate, could be used as it has lower cost. Besides that, their therapeutic success has been reported in various fields of medicine and biomedical sciences $^{13}$.

Considering this possibility, the objective of this study is to evaluate the effect of ethyl-cyanoacrylate in the treatment of anal fistulas in rats, with or without prior application of seton.

\section{Methods}

This research was approved by Ethics Committee on Animal Experimentation of Universidade Federal do Mato Grosso do Sul.
Thirty Wistar rats (Rattus norvegicus), male, adults, weighing approximately 300 grams were used, from the animal colony of UFMS. The animals were kept according to all required ethical standards.

Anesthesia was induced by intraperitoneal administration of ketamine and xylazine, in the same syringe. The solution was comprised of $1.0 \mathrm{~mL}$ of $10 \%$ ketamine and 1.0 mlxylazine $2 \%$. For each $100 \mathrm{~g}$ of body weight was infused $0.1 \mathrm{~mL}$ of the anesthetic solution.

The fistula was created based on experimental model of anal fistula in rats ${ }^{14}$. The animals were placed in the supine position, with four members in abduction. The entire procedure was performed under sterile conditions, complying with all antisepsis care and sterilization of the surgical area.

A number five steel monofilament suture $\left(\right.$ Aciflex $\left.^{\circledR}\right)$ was passed through the anal sphincter muscle about $1 \mathrm{~cm}$ from the left side margin (Figure 1). After the skin punching by the needle, the steel wire was cut and tied loosely through rotation movements around the anal sphincter and remained in place for 30 days.

The animals were kept in cages containing two or three animals during the study period, with food and water ad libitum.

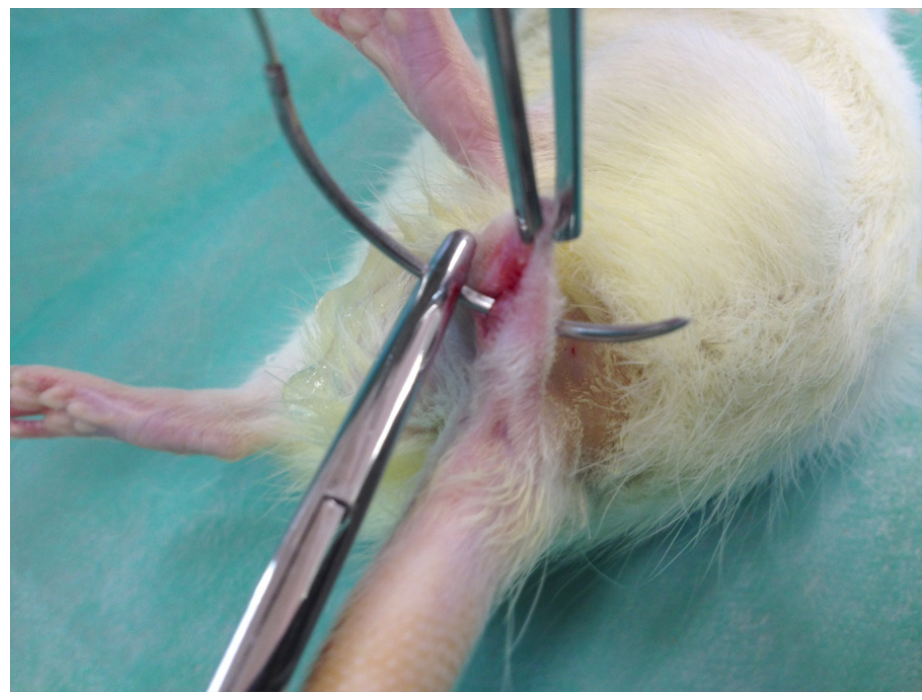

FIGURE 1 - Passage of the steel wire through the anal sphincter to create the fistula tract.

After 30 days of fistula creation, the steel wire were removed and three groups of 10 rats were formed.

- Group A (etyl-cyanoacrylate): Application of glue $\left(\right.$ Super Bonder ${ }^{\mathbb{R}}$ ) in the fistula by a needle, which was introduced in the fistula and connected to glue tube. During the withdrawal of the needle, the glue was instilled filling all the fistula tract. Each 
needle was used only once.

- Group B (seton + etyl-cyanoacrylate): Application of the seton (cotton 0 ) in the fistula tract, which remained into by 30 days (Figure 2); after this period, the seton was removed and the glue applyed by the same method described in group A. Both group A and B were evaluated on the thirtieth day after the application of glue.

- Group C (control): after removal of steel wire the animals were observed by 60 days.

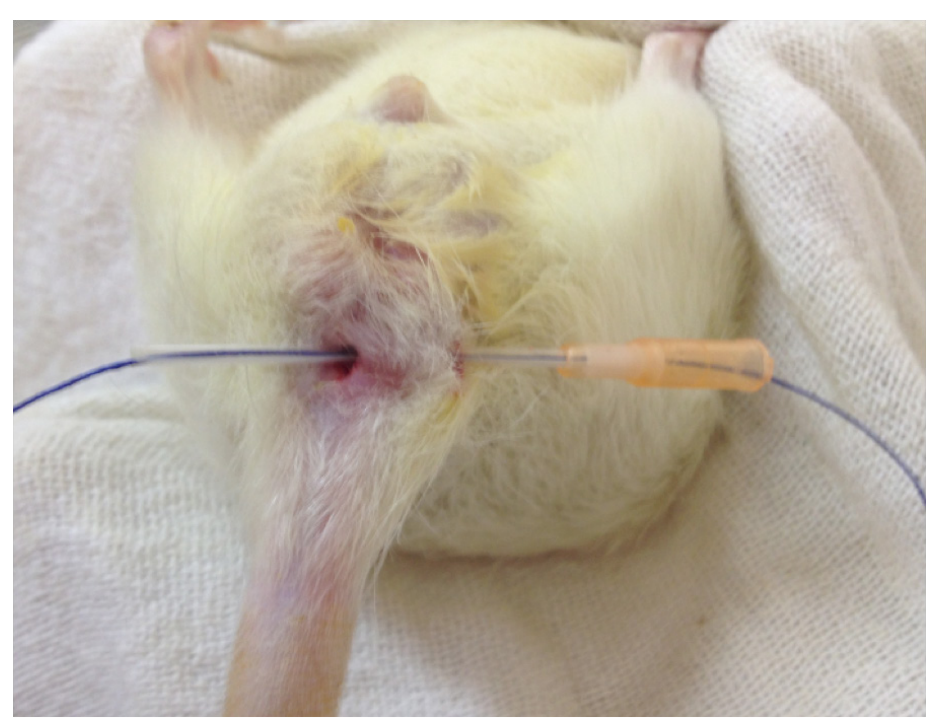

FIGURE 2 - Passage of cotton 0 through the fistula tract.

Euthanasia was accomplished by intracardiac sodium thiopental administration after sedation with ketamine and xylazine. After that, a circumferential incision around the anal canal was held with cold scalpel blade, including whole fístula tract. The samples were placed in a $10 \%$ solution of formaldehyde for subsequent histological analysis. The samples were prepared and stained with hematoxylin and eosin, the slides were examined by a pathologist as the persistence of fistula (Figure 3) or its complete closure. The results were statistically analyzed using the chi-square test by the GraphPad Prism software version 6.01 and SPSS version 22.0, considering significant $\mathrm{p}<0.05$.

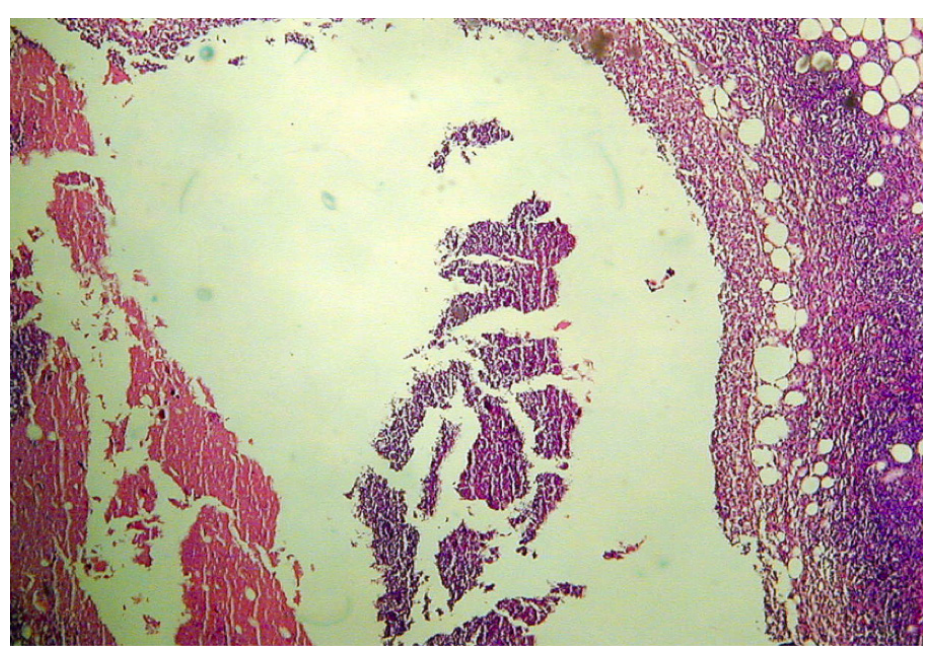

FIGURE 3 - Photomicrograph (HE, x 400) demonstrating persistence of fistula in one of the control group animals.

\section{Results}

One rat from group B died during the experiment, lasting nine animals in this group.

In group A the closure of the fístula tract was observed in seven rats, persisting fistula in three animals. In group B, fistulae completely healed in five rats, remaining open in four animals. In group $\mathrm{C}$, eight rats persisted with fistula and two had spontaneous healing (Figure 4). When examined all animals treated with ethylcyanoacrylate, with or without seton, compared with the control group, it was observed that 12 animals had fistula tract closure in groups $\mathrm{A}$ and $\mathrm{B}$ and only two in group $\mathrm{C}(\mathrm{p}=0.02)$ (Figure 5).

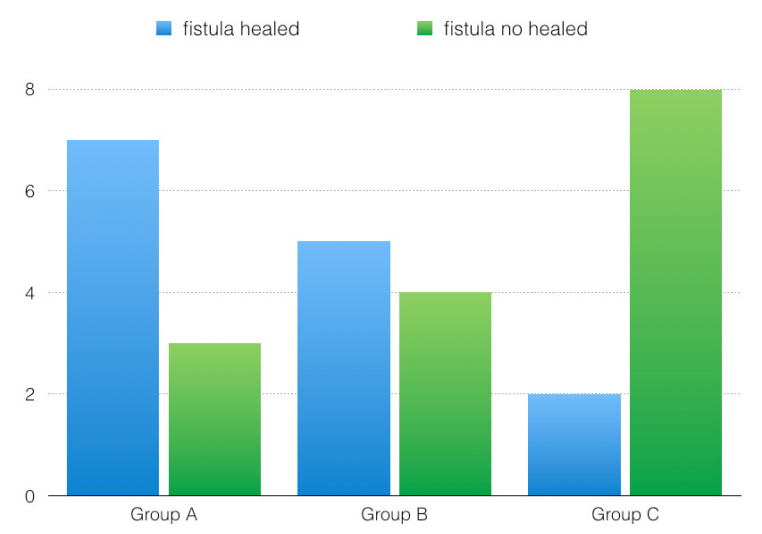

FIGURE 4 - Comparison between groups according to histological findings. $p$ value between groups $A$ and $B=0.51 ; p$ value between groups $\mathrm{A}$ and $\mathrm{C}=0.02 ; \mathrm{p}$ value between groups $\mathrm{B}$ and $\mathrm{C}=0.10$. 


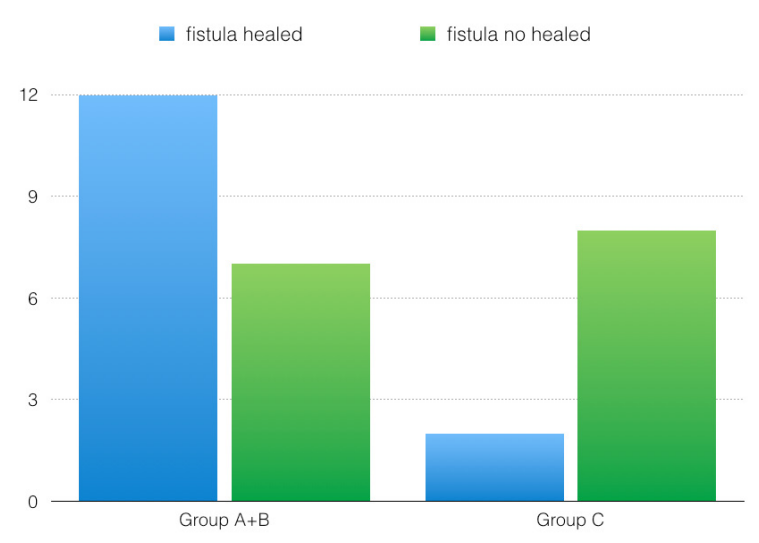

FIGURE 5 - Comparison between all animals treated with ethylcyanoacrylate and the control group according to histological findings $(\mathrm{p}=0.02)$.

\section{Discussion}

In the present study, we evaluated the effectiveness of ethyl-cyanoacrylate glue, associated or not to seton in the treatment of anal fistulae surgically produced in rats. Although still very limited number of publications, the use of cyanoacrylate in the treatment of anal fistula has shown promise, which was also oberved in this study. There was a statistically significant difference when comparing the group treated with glue and the control group. The previous seton placement not shown in this research any advantage, perhaps by allowing in some cases a partial epithelialization of the tract, which could reduce the effectiveness of the glue. Nevertheless, when joined the two groups treated with glue, regardless of prior application of seton and compared with the control group, there was a statistically significant advantage to the use of glue.

There is no publications with similar design to the present study, lasting difficult to compare and analyze the results. The most used biological adhesive is fibrin glue, which is composed of fibrinogen, thrombin and coagulation factors ${ }^{11}$. Its great advantage over traditional surgical methods is the absence of fecal incontinence, however, its success rate varies from $30 \%$ to $50 \%{ }^{15}$. In a recent study, Atul Mishra et al. ${ }^{11}$ demonstrated cure rate in six months of $57.14 \%$ in the treatment of high fistulae and $81.25 \%$ in low fistulae. Despite the good results reported by some authors, fibrin glue has limited use due to the high $\operatorname{cost}^{12}$.

Barillari et al. ${ }^{17}$ treated 21 patients with glue composed of N-butyl-2-cyanoacrylate and Metacrilosisolfolano (Glubran ${ }^{\circledR} 2$ ). Seven of these patients suffered from simple anal fistula and 14 complex anal fistula. The authors obtained after 18 months of follow-up, a cure rate of $90.2 \%(19 / 21)$, including those patients requiring more than one injection of glue. Complications such as bleeding, perineal abscess and fistula recurrence were observed.

During two years Queralto et al. ${ }^{18}$ used a synthetic glue Glubran ${ }^{\circledR} 2$ (N-butyl-2-cyanoacrylate and Metacrilosisolfolano) treatment of 34 patients with high anal fistula. Patients were followed by physical examination on 1st, 3rd and 6th month, and by telephone interview at one and two years. The cure rate in a month was $67.6 \%$. None of the 23 patients had fecal incontinence and remained free of recurrence over the average period of 34 months follow-up

Jain et al. ${ }^{19}$ treated 20 patients with low anal fistulas by cyanoacrylate glue application in the fistula. These patients were followed clinically for up to six months. Seventeen patients $(85 \%)$ achieved a cure with just one application of the adhesive.

Analyzing the literature it is observed that there is a good response to some glues, however, in addition to its high cost there are differences between its components. The ethyl-cyanoacrylate, used in this study, still needs further studies to confirm its effectiveness, however, if found results similar to those presented here, this could become a good option since its cost is lower than the other compositions.

\section{Conclusions}

The use of ethyl-cyanoacrylate glue was effective in closing anal fistulae in rats. There was no advantage in the prior application of seton.

\section{References}

1. Bubbers EJ, Cologne KG. Management of complex anal fistulas. Clin Colon Rectal Surg. 2016;29(1):43-9. doi: 10.1055/s-00351570392.

2. Parés D. Pathogenesis and treatment of fistula in ano. Br J Surg. 2011;98(1):2-3. doi: 10.1002/bjs.7341.

3. Ommer A, Herold A, Berg E, Fürst A, Sailer M, Schiedeck T. Cryptoglandular anal fistulas. Dtsch Arztebl Int. 2011;108(42):70713. doi: 10.3238/arztebl.2011.0707.

4. Martins I, Pereira JC. Supurações perianais abscessos e fístulas anais. Rev Port Coloproctol. 2010;7(3):118-24.

5. Sheikh P. Controversies in fistula in ano. Indian J Surg. 2012;74(3):217-20. doi: 10.1007/s12262-012-0594-5.

6. Bleier JIS, Moloo H. Current management of cryptoglandular fistula-in-ano. World J Gastroenterol. 2011;17(28):3286-91. doi: 10.3748/wjg.v17.i28.3286.

7. Damin DC, Rosito MA, Contu PC, Tarta C. Fibrin glue in the management of complex fistula. Arq Gastroenterol. 2009;46(4):3003. doi: 10.1590/S0004-28032009000400010.

8. Meinero P, Mori L. Video-assisted anal fistula treatment (VAAFT): a novel sphincter-saving procedure for treating complex anal fistulas. 
Tech Coloproctol. 2011;15:417-22. doi: 10.1007/s10151-0110769-2.

9. JacobTJ,PerakathB, KeighleyMR. Surgicalintervention foranorectal fistula. Cochrane Database Syst Rev. 2010;12;(5):CD006319. doi: 10.1002/14651858.CD006319.pub2.

10. Fernandez OV, Urbina LAE. Ligation of intersphincteric fistula tract: what is the evidence in a review? World J Gastroenterol. 2013;19(40):6805-13. doi: 10.3748/wjg.v19.i40.6805.

11. Mishra A, Shah S, Nar AS, Bawa A. The role of fibrin glue in the treatment of high and low fistulas in ano. J Clin Diagn Res. 2013;7(5):876-9. doi: 10.7860/JCDR/2013/5387.2964.

12. Cavichiolo JB, Buschle M, Carvalho B. Comparison of fibrin adhesives prepared by 3 different methods. Int Arch Otorhinolaryngol. 2013;17(1):62-5. doi: 10.7162/S1809-97772013000100011.

13. Oliveira CL, Santos CHM, Bezerra FMM, Bezerra MM, Rodrigues LL. Utilização de adesivos de cianoacrilatos em suturas de pele. Rev Bras Cir Plast. 2010;25(3):573-6. doi: 10.1590/S198351752010000300030.

14. Arakaki MS, Santos CHM, Falcão GR, Cassino PC, Nakamura RK, Gomes NF, Santos RGC. Experimental model of anal fistula in rats. J Coloproctol. 2013;33(3):135-8. doi: 10.1016/j.jcol.2013.04.005.

15. Paulo FL. O emprego da cola de fibrina no tratamento das fístulas anais. Rev Bras Coloproctol. 2006;26(1):86-8. doi: 10.1590/S010198802006000100012.

16. D'Assumpção EA. Cola de cianoacrilato de baixo custo em cirurgia plástica. Rev Soc Bras Cir Plast. 2008;23(1):22-5.

17. Barillari P, Basso L, Larcinese A, Gozzo P, Indinnimeo M. Cyanoacrylate glue in the treatment of ano-rectal fistulas. Int $\mathrm{J}$ Colorectal Dis. 2006 Dec;21(8):791-4. PMID: 16625375.

18. Queralto M, Portier G, Bonnaud G, Chotard JP, Cabarrot P, Lazorthes F. Efficacy of synthetic glue treatment of high crypoglandular fistulain-ano. Gastroenterol Clin Biol. 2010;34(8):477-82. doi: 10.1016/j. gcb.2009.12.010.

19. Jain SK, Kaza RC, Pahwa M, Bansal S. Role of cyanoacrylate in the management of low fistula in ano: a prospective study. Int J Colorectal Dis. 2008;23(4):355-8. PMID: 18071718.

\section{Correspondence:}

Carlos Henrique Marques dos Santos

Rua Dr Abdalla Duailibi, 264/lote 11/casa 7

79037230 Campo Grande - MS Brasil

chenriquems@yahoo.com.br

Received: Feb 22, 2016

Review: Apr 19, 2016

Accepted: May 18, 2016

Conflict of interest: none

Financial source: none

${ }^{1}$ Research performed at Laboratory of Experimental Surgery, Department of Surgery, Universidade Federal do Mato Grosso do Sul (UFMS), Campo Grande-MS, Brazil. 